\title{
Choledocholithiasis comorbidity with Clonorchis sinensis: A case report
}

\author{
Ping Shao ${ }^{1}$ and Qing Chen $^{1}$ \\ ${ }^{1}$ Cheng Fei Hospital
}

December 4, 2021

\begin{abstract}
Coexisting gallbladder stones, common bile duct stones and Clonorchis sinensis infection is rare. Most radiologists and surgeons have low awareness and diagnostic suspicion of C. sinensis infection before opting for surgery.
\end{abstract}

\section{Choledocholithiasis comorbidity with Clonorchissinensis: A case report}

Ping Shao, Qing Chen

Ping Shao, Qing Chen, Department of General Surgery, Cheng Fei Hospital, Chengdu 650091, Sichuan Province, China

Corresponding author: Qing Chen, MD, Chief Doctor, Department of General Surgery, Cheng Fei Hospital, No. 105, Jingyi Road, Chengdu 650091, Sichuan Province, China. chenqing4635@163.com

ORCID number: Ping Shao (0000-0002-2793-831X); Qing Chen (0000-0002-8119-9116).

Author contributions: Shao P performed the data analyses and wrote the manuscript; Chen Q designed the study and drafted the initial manuscript.

Supported by no dedicated source of funding

Conflict-of-interest statement: The authors declare that they have no conflicting interests.

Abstract

BACKGROUND

Coexisting gallbladder stones, common bile duct stones and Clonorchis sinensis infection is rare. Most radiologists and surgeons have low awareness and diagnostic suspicion of $C$. sinensis infection before opting for surgery.

\section{CASE SUMMARY}

A 39-year-old man was admitted to our department with complaint of right upper quadrant abdominal pain of $5 \mathrm{~h}$ duration. Physical examination revealed tenderness in the upper right abdomen and a positive Murphy sign. Increasing transaminase and bilirubin levels were the major laboratory findings. Preoperative imaging showed gallbladder stones, a common bile duct stone with slight dilatation of the intrahepatic bile ducts, and a blurred lower common bile duct. During surgery, an active parasite was found in the common bile duct. The final diagnosis was cholelithiasis with comorbid $C$. sinensis infection.

\section{CONCLUSION}


Preoperative imaging that reveals nonspecific changes associated with choledocholithiasis should increase suspicion of biliary parasite infection.

Key Words: Choledocholithiasis; Gallstones; Cholangitis; Clonorchis sinensis ; Case report INTRODUCTION

C. sinensis infection is frequently reported in East Asian countries, including China, Korea, Japan, and Vietnam. Clonorchiasis is most often caused by transmission of the adult flukes of $C$. sinensis to humans from freshwater $f_{i s h}{ }^{[1]}$, which subsequently parasitize the biliary system ${ }^{[2]}$.C. sinensis infection is often complicated clinically by acute cholangitis. Some studies have reported that clonorchiasis is related to hepatobiliary morbidity ${ }^{[3,4,5]}$ and cholangiocarcinoma ${ }^{[6,7]}$. The clinical symptoms of clonorchiasis have no obvious specificity, and can easily lead to missed diagnosis and misdiagnosis.

A case of choledocholithiasis comorbid with $C$. sinensis was admitted to Cheng Fei Hospital in Sichuan in May 2021, and is reported here.

\section{CASE PRESENTATION}

Chief complaints

A 39-year-old man complained of right upper quadrant abdominal pain of $5 \mathrm{~h}$ duration.

History of present illness

The patient reported having developed sudden pain in the upper right abdomen without obvious cause and accompanied by back-radiating pain, nausea, vomiting, and abdominal distension.

History of past illness

The patient's past medical history was unremarkable.

Personal and family history

Personal and family histories of the patient were unremarkable.

Physical examination upon admission

The patient's pulse was regular, temperature was normal, and blood pressure was $11.9 / 8.5 \mathrm{kPa}$. On examination, the patient had slightly yellow skin and sclera, tenderness in the right upper abdomen, and no obvious rebound pain or muscle tension. The Murphy sign was positive.

Laboratory examination

The initial workup showed a white blood cell (WBC) count of $11.4 \times 10^{9} / \mathrm{L}, 94.8 \%$ neutrophils, and Creactive protein (CRP) of $22.2 \mathrm{mg} / \mathrm{L}$. Biochemical evaluation revealed alanine aminotransferase (ALT) of $352 \mathrm{U} / \mathrm{L}$, aspartate transaminase (AST) of $435 \mathrm{U} / \mathrm{L}$, total bilirubin (TBil) of $40.8 \mu \mathrm{mol} / \mathrm{L}$, direct bilirubin (DBil) of $20.2 \mu \mathrm{mol} / \mathrm{L}$, alkaline phosphatase (ALP) of $188 \mathrm{U} / \mathrm{L}$, and glutamine acyltransferase (GGT) of 422 $\mathrm{U} / \mathrm{L}$. Two days later, re-testing of hematological and biochemical parameters revealed WBC count of $7.2 \times$ $10^{9 / \mathrm{L}, 76.4 \%}$ neutrophils, CRP of $16.2 \mathrm{mg} / \mathrm{L}$, ALT of $934 \mathrm{U} / \mathrm{L}$, AST of $415 \mathrm{U} / \mathrm{L}$, TBil of $127.3 \mu \mathrm{mol} / \mathrm{L}$, DBil of $69.5 \mu \mathrm{mol} / \mathrm{L}$, ALP of $272 \mathrm{U} / \mathrm{L}$, and GGT of $571 \mathrm{U} / \mathrm{L}$ (Table 1).

Imaging examination

Abdominal computed tomography showed gallbladder stones, wall thickening, and choledocholithiasis with slight dilatation of the intrahepatic bile ducts (Figure 1A). Magnetic resonance cholangiopancreatography (MRCP) revealed gallbladder stones with slight dilatation of the intrahepatic bile ducts, and blurred lower common bile duct (Figure 1B).

FINAL DIAGNOSIS 
We considered that the high bilirubin level was caused by the common bile duct abnormalities and gallbladder stones. An active parasite was found during exploration of the common bile duct (Figure 2). Subsequent pathological examination revealed C. sinensis .

\section{TREATMENT}

Laparoscopic cholecystectomy and common bile duct exploration were performed, and a T-tube was placed for bile drainage. After surgery, the patient was given anti-infective, hepatoprotective, choleretic and antispasmodic treatment, as well as praziquantel $(80 \mathrm{mg} / \mathrm{kg} / \mathrm{d}$ for $3 \mathrm{~d})$ for deworming.

\section{OUTCOME AND FOLLOW-UP}

In the days following surgery, adult worms were not observed in the bile duct drainage. Liver function and hematological indicators gradually recovered after surgery (Table 1). No obvious bile duct abnormalities were seen on MRCP (Figure 3). The T-tube was removed $30 \mathrm{~d}$ after surgery. The patient was followed for $6 \mathrm{mo}$ and reported experiencing no discomfort.

\section{DISCUSSION}

C. sinensis is most often reported in east Asian countries, including China, Korea, Japan and Vietnam, with approximately 35 million infected individuals ${ }^{[8]}$. Some studies have estimated that 12.49 million people have been infected with $C$. sinensis in China ${ }^{[9]}$. C. sinensis is mainly transmitted to humans from ingestion of freshwater fish ${ }^{[1]}$. However, our patient had no history of eating raw freshwater fish. Because of the nonspecific and atypical symptoms, C. sinensis infection has always been under-recognized, and often leads to clonorchiasis ${ }^{[10]}$. This patient had common bile duct stones with acute cholangitis and gallbladder stones with acute cholecystitis. Intraoperative exploration of the common bile duct revealed $C$. sinensis . It is not easy to diagnose $C$. sinensis infection before surgery. The preoperative MRCP examination of this patient showed no dilation of the common bile duct. Lack of clarity in the lower common bile duct was unlike the dilation caused by conventional common bile duct stones ${ }^{[11]}$. Based on that, the possibility of bile duct parasites should be considered by radiologists and surgeons.

After surgery, the patient was treated with routine anti-infective agents and administered hepatoprotective and choleretic drugs, and praziquantel ${ }^{[12]}$. The T-tube did not drain the $C$. sinensis body, and deworming treatment was given. After treatment, liver function improved significantly. Coexisting gallbladder stones, common bile duct stones, and C. sinensis is relatively rare. Previous studies and case reports ${ }^{[5,9,11]}{ }_{\text {suggest }}$ that $C$. sinensis might cause gallbladder stones by weakening the function of the gallbladder and causing the precipitation of bilirubinate, calcium carbonate crystals, and mucin on $C$. sinensis eggs. It is possible that the common bile duct stone and gall bladder stones in our patient were caused by the $C$. sinensis infection.

\section{CONCLUSION}

Our experience with this case suggests that if preoperative imaging reveals nonspecific changes associated with choledocholithiasis, the possibility of biliary parasite infection should be suspected.

\section{ACKNOWLEDGEMENTS}

We are grateful to the patient for allowing publication of this case report.

\section{REFERENCES}

1. Lun ZR, Gasser RB, Lai DH, Li AX, Zhu XQ, Yu XB, Fang YY. Clonorchiasis: a key foodborne zoonosis in China. Lancet Infect Dis 2005;5:31-41 [PMID: 15620559 DOI: 10.1016/S1473-3099(04)01252-6]

2. Qian MB, Utzinger J, Keiser J, Zhou XN. Clonorchiasis. Lancet 2016;387:800-810 [PMID: 26299184 DOI: 10.1016/S0140-6736(15)60313-0]

3. Qian MB, Li HM, Jiang ZH, Yang YC, Lu MF, Wei K, Wei SL, Chen Y, Zhou CH, Chen YD, Zhou XN. Severe hepatobiliary morbidity is associated with Clonorchis sinensis infection: The evidence from a cross- 
sectional community study. PLoS Negl Trop Dis 2021;15:e0009116 [PMID: 33507969 DOI: 10.1371/journal.pntd.0009116]

4. Choi D, Lim JH, Lee KT, Lee JK, Choi SH, Heo JS, Choi DW, Jang KT, Lee NY, Kim S, Hong ST. Gallstones and Clonorchis sinensis infection: a hospital-based case-control study in Korea. J Gastroenterol Hepatol 2008;23:e399-404 [PMID: 18070015 DOI: 10.1111/j.1440-1746.2007.05242.x]

5. Qiao T, Ma RH, Luo XB, Luo ZL, Zheng PM. Cholecystolithiasis is associated with Clonorchis sinensis infection. PLoS One 2012;7:e42471 [PMID: 22905137 DOI: 10.1371/journal.pone.0042471]

6. Chang JI, Lee K, Kim D, Yang JI, Park JK, Choi K, Kang SH, Lee KH, Lee KT, Lee JK, Park SM, Park JK. Clinical Characteristics of Clonorchis sinensis-Associated Cholangiocarcinoma: A Large-Scale, SingleCenter Study. Front Med (Lausanne) 2021;8:675207 [PMID: 34124104 DOI: 10.3389/fmed.2021.675207]

7. Na BK, Pak JH, Hong SJ. Clonorchis sinensis and clonorchiasis. Acta Trop 2020;203:105309 [PMID: 31862466 DOI: $10.1016 /$ j.actatropica.2019.105309]

8. Hong ST, Fang Y. Clonorchis sinensis and clonorchiasis, an update. Parasitol Int 2012;61:17-24 [PMID: 21741496 DOI: $10.1016 /$ j.parint.2011.06.007]

9. Wang N, Tang B, Hao YH, Bai X, Wang XL, Li YX, Yang Y, Li SC, Hao S, Wang XY, Liu MY, Liu XL. Acute shock caused by Clonorchis sinensis infection: a case report. BMC Infect Dis 2019;19:1014 [PMID: 31783809 DOI: 10.1186/s12879-019-4644-5]

10. Lim JH. Liver flukes: the malady neglected. Korean J Radiol 2011;12:269-279 [PMID: 21603286 DOI: 10.3348/kjr.2011.12.3.269]

11. Liu XL, Zhu GL, Cai CN, Lv ZY, Li J. Clonorchiasis sinensis detected by laparoscopic exploration of biliary tracts in two patients with obstructive jaundice. BMC Infect Dis 2019;19:33 [PMID: 30621611 DOI: 10.1186/s12879-019-3679-y]

12. Doenhoff MJ, Hagan P, Cioli D, Southgate V, Pica-Mattoccia L, Botros S, Coles G, Tchuem Tchuenté LA, Mbaye A, Engels D. Praziquantel: its use in control of schistosomiasis in sub-Saharan Africa and current research needs. Parasitology 2009;136:1825-1835 [PMID: 19281637 DOI: 10.1017/S0031182009000493]

\section{Figure Legends}

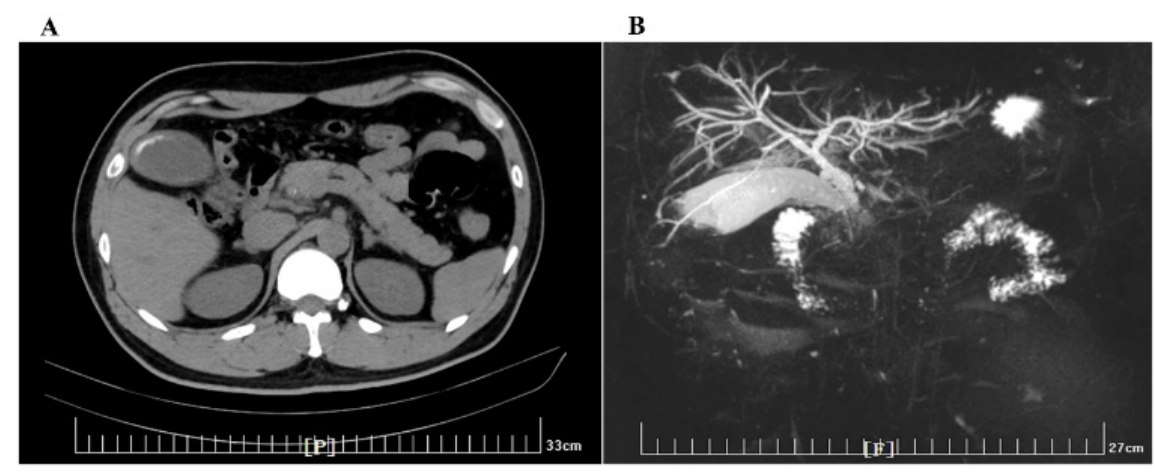

Figure 1 Preoperative imaging. A: Computed tomography of the gallbladder and common bile duct stones; B: Magnetic resonance cholangiopancreatography showing slight dilation of the intrahepatic bile duct and the unclear lower part of the common bile duct. 


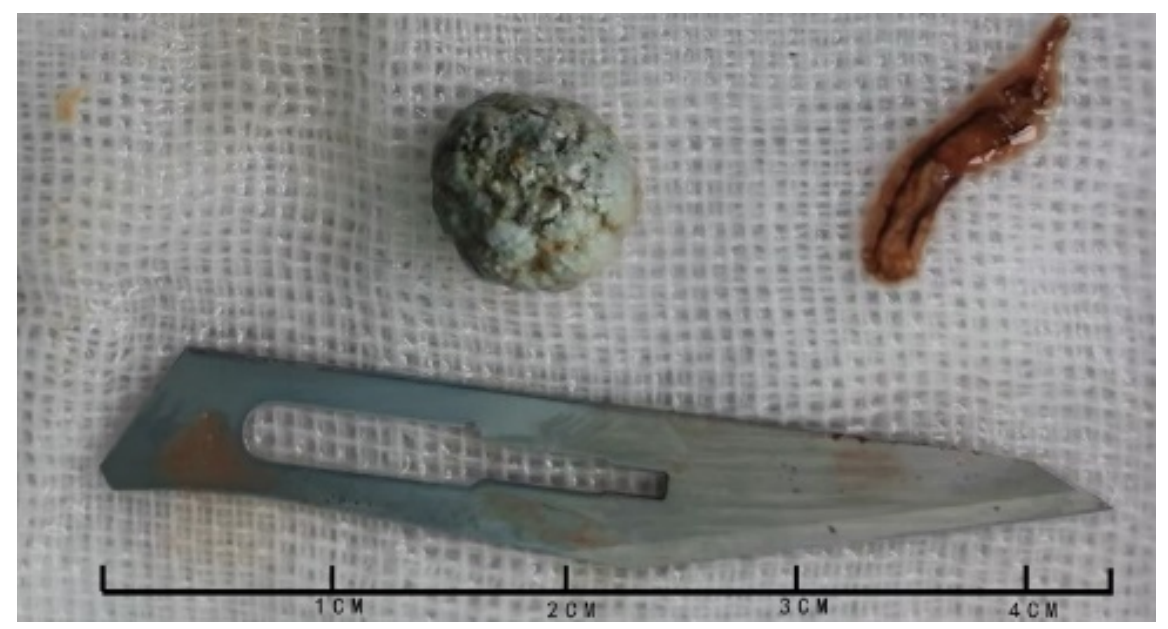

Figure 2 An active parasite and a stone found upon surgical exploration of the common bile duct.

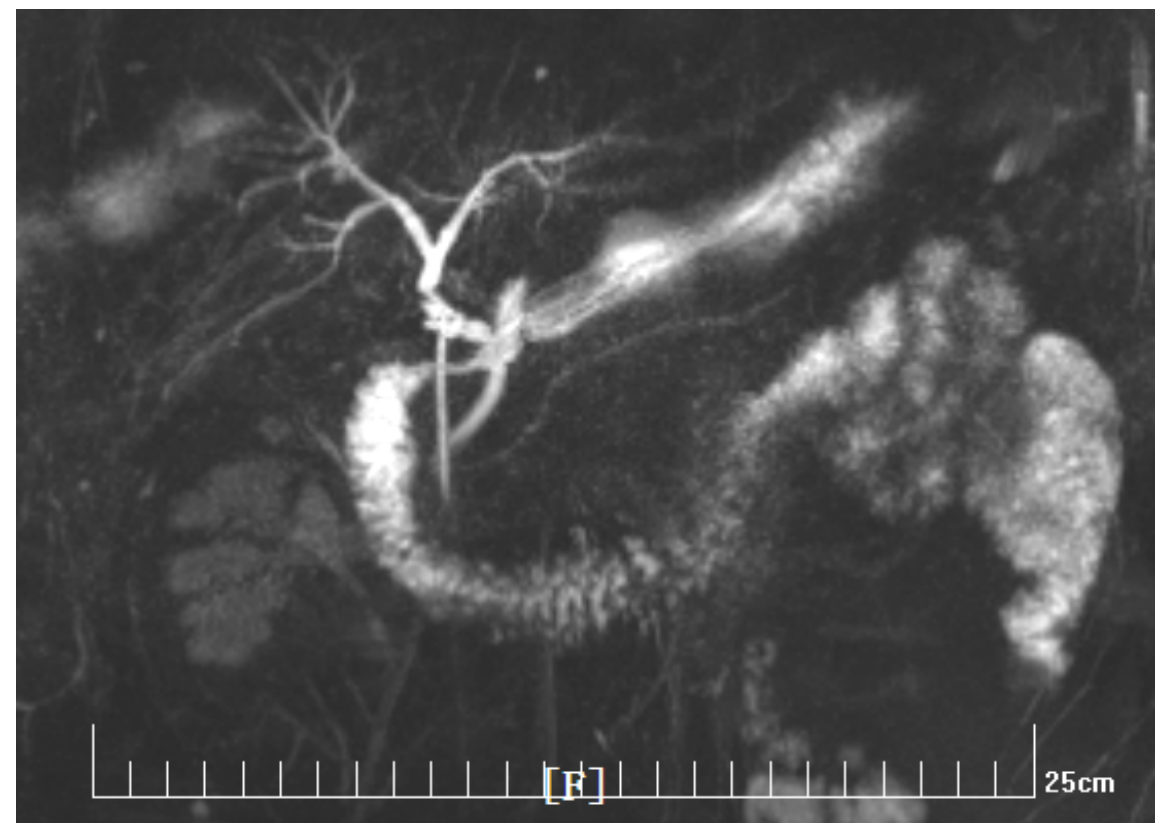

Figure 3 No obvious abnormalities in the bile ducts were visible by magnetic resonance cholangiopancreatography at $30 \mathrm{~d}$ after surgery.

\begin{tabular}{llllll}
\hline Variable & Preoperative day & Preoperative day & Preoperative day & Preoperative day & Preoperative \\
\hline & $\mathbf{1}$ & $\mathbf{2}$ & $\mathbf{2}$ & & \\
$\mathrm{WBC}, \times 10^{9} / \mathrm{L}$ & 11.4 & 7.2 & 7.2 & & \\
$\mathrm{NEUT}, \times 10^{9} / \mathrm{L}$ & 10.8 & 5.5 & 5.5 & & \\
$\mathrm{NEUT}, \%$ & 94.8 & 76.4 & 76.4 & & \\
$\mathrm{CRP}, \mathrm{mg} / \mathrm{L}$ & 22.2 & 16.2 & 16.2 & \\
$\mathrm{ALT}, \mathrm{U} / \mathrm{L}$ & 352 & 934 & 934 & \\
$\mathrm{AST}, \mathrm{U} / \mathrm{L}$ & 435 & 415 & 415 &
\end{tabular}




\begin{tabular}{|c|c|c|c|c|c|}
\hline Variable & Preoperative day & Preoperative day & Preoperative day & Preoperative day & Preoperative \\
\hline TBil, $\mu \mathrm{mol} / \mathrm{L}$ & 40.8 & 127.3 & 127.3 & & \\
\hline $\mathrm{DBil}, \mu \mathrm{mol} / \mathrm{L}$ & 20.2 & 69.5 & & & 65.0 \\
\hline $\mathrm{ALP}, \mathrm{U} / \mathrm{L}$ & 188 & 272 & & & 284 \\
\hline GGT, U/L & 422 & 571 & & & 609 \\
\hline
\end{tabular}

Table 1 Preoperative and postoperative blood results

ALP: Alkaline phosphatase; ALT: Alanine aminotransferase; AST: Aspartate aminotransferase; CRP: Creactive protein; DBil: Direct bilirubin; GGT: Glutamine acyltransferase; NEUT: Neutrophils; TBil: Total bilirubin; WBC: White blood cell. 